\title{
Effects of a Novel, Transdiagnostic, Hybrid Ecological Momentary Intervention for Improving Resilience in Youth (EMIcompass): Protocol for an Exploratory Randomized Controlled Trial
}

Anita Schick ${ }^{1}$, Dipl-Psych, PhD; Isabell Paetzold ${ }^{1}$, MSc; Christian Rauschenberg ${ }^{1}$, MSc; Dusan Hirjak $^{2}$, MD; Tobias Banaschewski $^{3}$, MD, PhD; Andreas Meyer-Lindenberg ${ }^{2}$, MD, PhD; Jan R Boehnke ${ }^{1,4}$, PhD; Benjamin Boecking, Dipl-Psych, PhD, DClinPsy; Ulrich Reininghaus ${ }^{1,6,7}$, Dipl-Psych, MSc, PhD

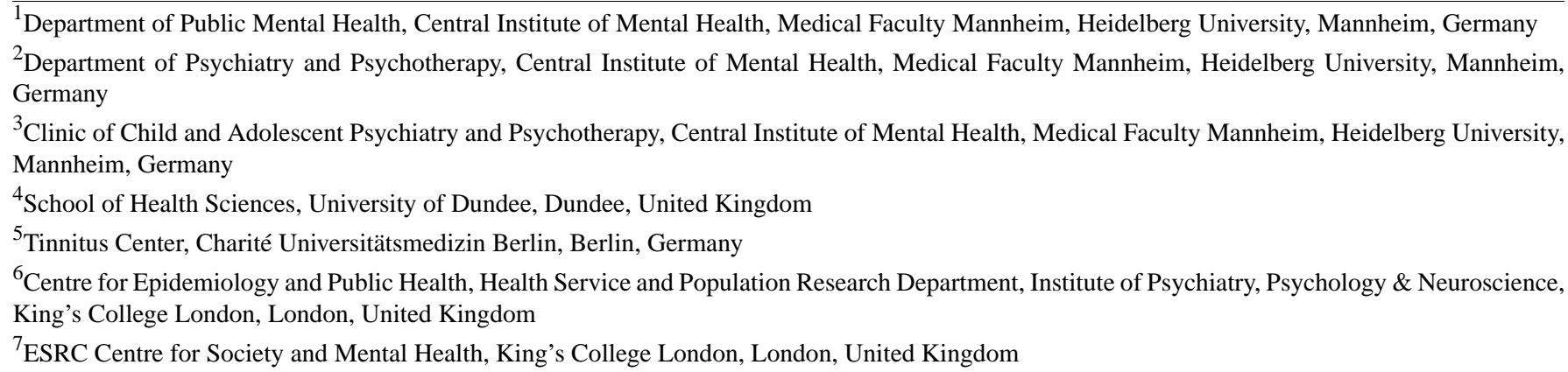

\section{Corresponding Author:}

Ulrich Reininghaus, Dipl-Psych, MSc, PhD

Department of Public Mental Health

Central Institute of Mental Health

Medical Faculty Mannheim, Heidelberg University

Square J5

Mannheim, 68159

Germany

Phone: 4962117031930

Email: ulrich.reininghaus@zi-mannheim.de

\section{Abstract}

Background: Most mental disorders first emerge in youth and, in their early stages, surface as subthreshold expressions of symptoms comprising a transdiagnostic phenotype of psychosis, mania, depression, and anxiety. Elevated stress reactivity is one of the most widely studied mechanisms underlying psychotic and affective mental health problems. Thus, targeting stress reactivity in youth is a promising indicated and translational preventive strategy for adverse mental health outcomes that could develop later in life and for improving resilience. Compassion-focused interventions offer a wide range of innovative therapeutic techniques that are particularly amenable to being implemented as ecological momentary interventions (EMIs), a specific type of mobile health intervention, to enable youth to access interventions in a given moment and context in daily life. This approach may bridge the current gap in youth mental health care.

Objective: This study aims to investigate the clinical feasibility, candidate underlying mechanisms, and initial signals of the efficacy of a novel, transdiagnostic, hybrid EMI for improving resilience to stress in youth-EMIcompass.

Methods: In an exploratory randomized controlled trial, youth aged between 14 and 25 years with current distress, a broad Clinical High At-Risk Mental State, or the first episode of a severe mental disorder will be randomly allocated to the EMIcompass intervention (ie, EMI plus face-to-face training sessions) in addition to treatment as usual or a control condition of treatment as usual only. Primary (stress reactivity) and secondary candidate mechanisms (resilience, interpersonal sensitivity, threat anticipation, negative affective appraisals, and momentary physiological markers of stress reactivity), as well as primary (psychological distress) and secondary outcomes (primary psychiatric symptoms and general psychopathology), will be assessed at baseline, postintervention, and at the 4-week follow-up. 
Results: The first enrollment was in August 2019, and as of May 2021, enrollment and randomization was completed (N=92). We expect data collection to be completed by August 2021.

Conclusions: This study is the first to establish feasibility, evidence on underlying mechanisms, and preliminary signals of the efficacy of a compassion-focused EMI in youth. If successful, a confirmatory randomized controlled trial will be warranted. Overall, our approach has the potential to significantly advance preventive interventions in youth mental health provision.

\section{Trial Registration: German Clinical Trials Register DRKS00017265;} https://www.drks.de/drks_web/navigate.do?navigationId=trial.HTML\&TRIAL_ID=DRKS00017265

International Registered Report Identifier (IRRID): DERR1-10.2196/27462

(JMIR Res Protoc 2021;10(12):e27462) doi: 10.2196/27462

\section{KEYWORDS}

experience sampling methodology (ESM); ecological momentary assessment (EMA); mobile intervention; at-risk individuals; smartphone training; blended care; mental health; stress reactivity; mobile phone

\section{Introduction}

\section{Background}

Youth is a critical life period, and most mental disorders have their onset before the age of 25 years [1]. In the early stages of psychopathology, subthreshold expressions of symptoms may occur, reflecting an extended phenotype in the general population that is often transdiagnostic in nature, spanning from subthreshold expressions of anxiety, depression, and mania to psychotic experiences [2-4]. This extended transdiagnostic phenotype may, in turn, be associated with a range of subsequent psychopathological outcomes or exit syndromes later in life $[2,3]$. On the basis of emerging evidence on the transdiagnostic dimensions of psychopathology [5-10], dimensional classification systems with transdiagnostic high-order spectra that place individuals on a continuum of mental ill-health have recently been proposed, including the Hierarchical Taxonomy of Psychopathology [11-14], and clinical staging models have been proposed considering the overlapping and nonspecific nature of early psychopathology [15-18]. For example, Hartmann et al [16] in their clinical staging model, distinguish three stages of early mental health problems, that is, current psychological distress (stage 1a), a broad Clinical High At-Risk Mental State (CHARMS) with attenuated symptoms of psychosis, mania, or depression (stage 1b), and a first episode of severe mental disorder (stage 2). Moreover, mental disorders in youth aged 10-24 years have been reported to be the leading cause of disease burden in high-income countries [19], underlining the importance of early intervention and prevention. However, access to care remains deficient, with only 1 in 5 youth with mental health problems having access to mental health services $[20,21]$. Thus, there is a strong need for easily accessible, low-threshold, preventive interventions in the provision of youth mental health services.

Recent rapid advances in digital technologies have led to the development of novel mobile health (mHealth) assessment and intervention techniques, of which ecological momentary assessments (EMAs) [22,23] and ecological momentary interventions (EMIs) [23-28] are, arguably, among the most powerful [26,28]. EMIs such as Acceptance and Commitment Therapy in Daily Life [29,30], recently also referred to as just-in-time adaptive interventions [31], provide a unique opportunity to deliver youth-friendly, adaptive, personalized, real-time transfer of intervention components to individuals' daily lives. EMIs enable youth to access interventions tailored to what a young person needs in a given moment and context through interactive sampling and administration of specific training components [26,27,32]. To this end, EMIs build on real-time data acquired through EMA, a structured digital diary technique that measures moment-to-moment fluctuations in experience, behavior, and-when coupled with electrocardiography (ECG) and actigraphy sensors-physiological markers in daily life to offer training components that are adapted to the person, moment, and context based on EMA data. Therefore, EMIs are amenable to enhancing access to mental health services for youth depending on their needs and preferences. Indeed, youth - as the generation of digital natives - already make regular use of mHealth apps and are more likely to do so when experiencing psychological distress [33]. However, most mHealth apps that are currently available in major app stores are not evidence-based, often use problematic data sharing and privacy practices, and sometimes contain harmful content [34-36]. As reviewed recently, there is evidence on the effectiveness of mindfulness-based EMI for stress reduction [37] and reduction of psychotic experiences $[30,38,39]$. Furthermore, there is evidence for higher compliance and greater effectiveness of hybrid interventions that include both digital and face-to-face intervention components with research staff or clinicians [40,41].

Underlying transdiagnostic mechanisms may be important intervention targets in youth to prevent transition to and incidence of severe mental disorder. The most widely studied transdiagnostic mechanisms are (1) elevated stress reactivity (ie, more intense emotional reactions to minor stressors in daily life), (2) heightened interpersonal sensitivity, and (3) enhanced threat anticipation. There is evidence that stress reactivity is elevated in individuals with higher familial or psychometric risk, individuals with an ultrahigh risk state for psychosis, first-episode psychosis, severe and enduring psychosis [42-45], as well as with depressive disorder [46-48], mania, and bipolar disorder [49-51]. Moreover, some evidence suggests that differential reactivity to momentary stressors may reflect a risk and resilience mechanism [44,52-54]. Heightened interpersonal sensitivity is another putative transdiagnostic psychological mechanism that has been characterized by an enduring sense 
of feeling vulnerable in the presence of others [43,55]. Interpersonal sensitivity has been previously reported as a relevant psychological mechanism in individuals with ultrahigh risk, paranoia, and psychotic disorders $[55,56]$ as well as in individuals with affective disturbances, including depression, anxiety, and bipolar disorder [57-59].

Furthermore, our recent EMA findings extended beyond elevated interpersonal and socioenvironmental sensitivity and, consistent with previous research on psychotic, depressive, and anxiety disorders [60-65], also indicated that enhanced anticipation of threat might be an important mechanism in the development of psychosis $[43,44]$. These mechanisms have been implicated in a range of adverse mental health outcomes, which we have found to overlap considerably $[2,5,6,66]$ and, as noted above, often manifest at a developmentally early stage in adolescence. Thus, developing EMIs targeting these candidate mechanisms underlying a dimensional transdiagnostic and extended phenotype of psychosis, mania, depression, and anxiety in youth is a promising indicated strategy [67] for preventing transition to, and incidence of, severe mental disorders, which, if effective, will be associated with substantial public health gains.

Compassion-focused interventions are third-wave cognitive behavioral therapy (CBT) approaches that use a wide range of innovative therapeutic techniques for enhancing emotional resilience by activating emotion regulation systems related to self-compassion, self-acceptance, and positive affect rather than those related to stress, threat, anxiety, and depression [68-70]. Indeed, there is meta-analytic evidence on compassion-focused interventions treating various conditions [71-73], such as depression and anxiety [74], psychosis [75], and general distress [76]. Compassion-focused interventions involve the use of techniques that seek to access emotion regulation processes through imagery rather than rational understanding [68,69]. In doing so, compassion-focused interventions aim to enhance emotional resilience by developing specific affective regulation patterns and, thereby, reduce reactivity to stress, hypervigilance for threat, interpersonal sensitivity, and negative affective appraisals. Experimental evidence indicates that compassion-focused intervention techniques can reduce negative affect and paranoia in moments of high stress [77,78]. Therefore, compassion-focused interventions are particularly promising for targeting these putative transdiagnostic mechanisms. Building on these pieces of evidence, we have recently developed a novel, accessible, transdiagnostic, compassion-focused, hybrid intervention to enhance resilience in youth with early mental health problems - the EMIcompass intervention [53], which consists of an EMI plus face-to-face training sessions. Although there is preliminary evidence on the feasibility and initial therapeutic effects of the EMIcompass intervention from an uncontrolled pilot study [53], robust evidence on the underlying mechanisms, feasibility, and initial signals of efficacy of EMIcompass from an exploratory trial is pending.

\section{Objectives}

Against this background, this study will aim to examine the clinical feasibility, underlying mechanisms, and initial signals of efficacy of EMIcompass for improving resilience in an exploratory, randomized controlled trial (RCT) of youth with current psychological distress, a broad CHARMS, or a first episode of severe mental disorder. The EMIcompass intervention will be administered in addition to treatment as usual (TAU) in the experimental condition compared with a control condition of TAU only. Specifically, this study's aims are as follow:

1. to establish the clinical feasibility of the trial methodology and deliver the EMIcompass intervention to youth with early mental health problems (based on successful recruitment, assessment of inclusion criteria, randomization, retention in the assessment of outcomes, fidelity of delivering the intervention, compliance with the intervention protocol, satisfaction, and acceptability);

2. to detect initial signals of the efficacy of the EMIcompass intervention in reducing psychological distress (candidate primary outcome), primary (ie, psychotic, manic, anxiety, or depressive) symptoms, and general psychopathology (candidate secondary outcomes) at postintervention and 4-week follow-up;

3. to test the effects of the EMIcompass intervention on reducing stress reactivity (primary candidate mechanism), threat anticipation, interpersonal sensitivity, negative affective appraisals, resilience, self-compassion, emotion regulation, and physiological markers of stress reactivity (secondary candidate mechanisms) at postintervention and 4-week follow-up; and

4. to explore whether the effects of the EMIcompass intervention on psychological distress, primary (ie, psychotic, manic, anxiety, or depressive) symptoms, and general psychopathology are mediated via pathways through stress reactivity, threat anticipation, interpersonal sensitivity, negative affective appraisals, resilience, self-compassion, and emotion regulation.

\section{Methods}

\section{Study Design}

In an exploratory RCT, youth aged 14-25 years will be randomly assigned to the EMIcompass intervention in addition to TAU (experimental condition) or a control condition of TAU only, which will include routine mental health care. Participants will be recruited from mental health services in Mannheim, Germany, and via advertisements on the institute's webpage, Facebook, and Instagram and via local registries. Candidate mechanisms and outcomes will be assessed before randomization (at baseline), at the end of the 6-week intervention period (postintervention), and at the 4-week follow-up (ie, 4 weeks after completing the intervention period) by blinded assessors (Figure 1). Randomization will be conducted by an independent researcher using a computer-generated sequence. The assessment of outcomes and statistical analyses will be blinded to the treatment allocation. 
Figure 1. Study flowchart. EMA: ecological momentary assessment, collected eight times per day on 6 consecutive days (including self-reported and activity or electrocardiography sensor); $n$ denotes the total number of participants.

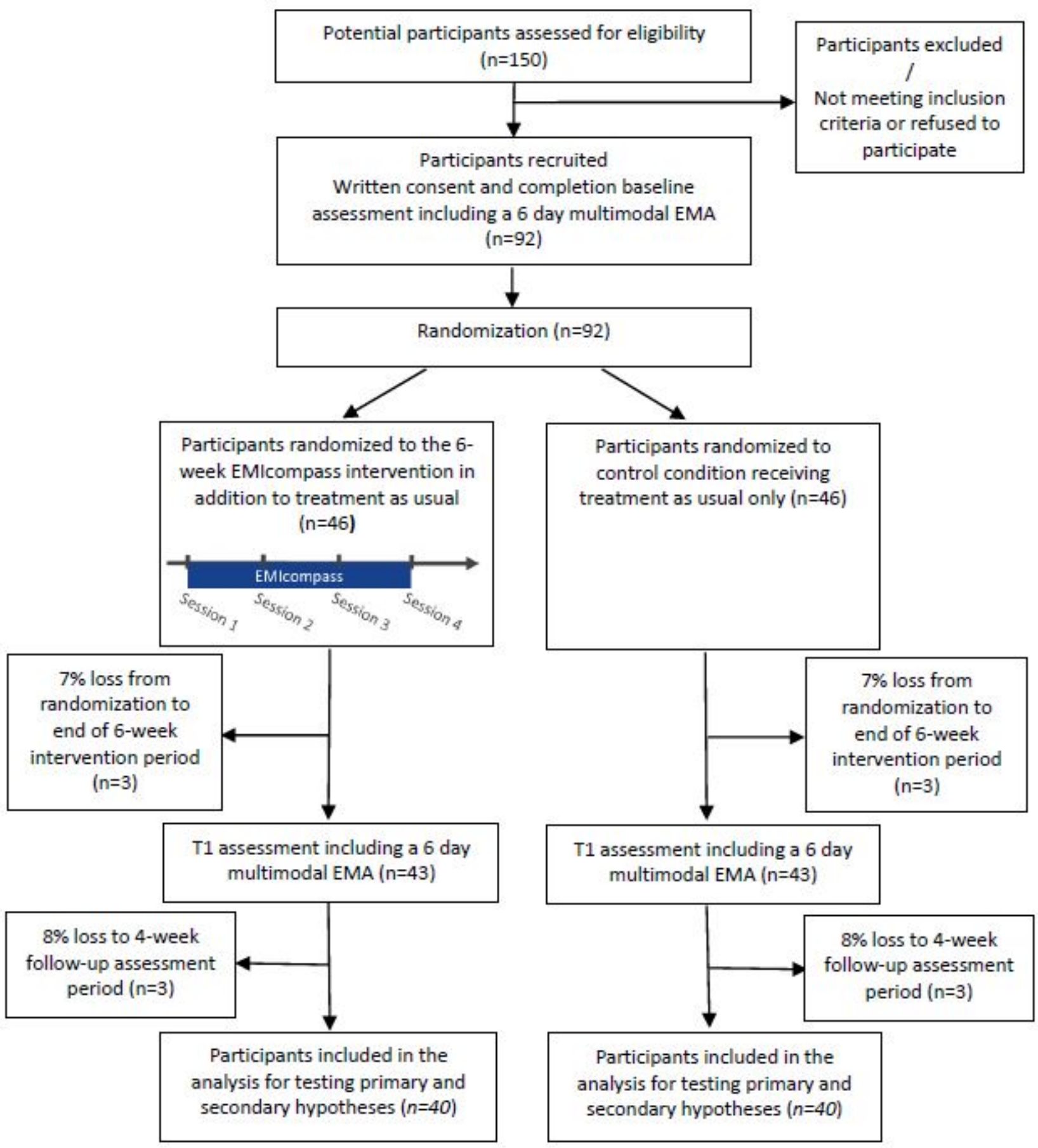

\section{Participants}

We will recruit and randomize 92 individuals with current psychological distress, CHARMS or a first episode of severe mental disorder based on a modified version of the clinical staging model by Hartmann et al [16]. Individuals presenting to mental health services at the Central Institute of Mental Health (CIMH), Mannheim, will be approached by a clinician who will provide initial information about the study. If the individual agrees, their treating clinician will pass on their contact details to the research team. In addition, individuals from the general population, who do not seek help from mental health services at CIMH, will be recruited for example, via

social media or local registries. All participants will then be contacted by the research team, and initial information about the study will be provided. Following this, individuals will be fully informed about the study, and written informed consent will be obtained by researchers with a master's degree in psychology (including parents or legal guardians for minors), which can be withdrawn at any time without any negative consequences. Eligibility will then be assessed in an interview using observer-rated measures (Structured Clinical Interview for Diagnostic and Statistical Manual of Mental Disorders, fifth edition (DSM-5) [79]; Comprehensive Assessment of At-Risk Mental State [80] completed by the researcher; and self-reported measures using the Kessler Psychological Distress Scale $[1,81])$. 
All participants will be reimbursed for their time and travel expenses at the end of the study.

\section{Ethics Approval and Consent to Participate}

The study, titled Efficacy of a novel, accessible, transdiagnostic, compassion-focused ecological momentary intervention for help-seeking youth (EMIcompass), has received ethical approval from the local ethics committee of the Medical Faculty Mannheim Heidelberg University (2017-602N-MA, date: September 7, 2017). Ethical approval was granted before funding was obtained, given that this is a requirement for project grants by the German Research Foundation. All participants and, in the case of individuals aged $<18$ years, parents or legal guardians will provide written informed consent before inclusion in the study. The sponsor has an insurance, which covers accidents on the journeys to the study appointments. However, no insurance covers harm from study participation, as this is expected to be of low risk.

\section{Inclusion and Exclusion Criteria}

Textbox 1 provides an overview on the inclusion and exclusion criteria, and Table 1 defines the inclusion criteria in more detail.

Textbox 1. Inclusion and exclusion criteria.

Inclusion criteria

- $\quad$ Age between 14 and 25 years

- Meeting criteria for one of the following stages (based on a modified version of the clinical staging model by Hartmann and colleagues [16]): individuals with current psychological distress (stage 1a), that is, a score of 20 or above on the Kessler Psychological Distress Scale [1,81], but no Clinical High At-Risk Mental State (stage 1b) or first episode of severe mental disorder (stage 2); individuals who meet criteria for a Clinical High At-Risk Mental State (stage 1b); individuals, who meet criteria for a first episode of psychotic disorder, bipolar disorder, severe depressive disorder or severe anxiety disorder according to according to the Diagnostic and Statistical Manual of Mental Disorders, fifth edition (DSM-5) (stage 2)

- High emotional reactivity assessed with a two-item self-report measure (instruction: "Please think of the most unpleasant event in the last week: (1) How sad, disappointed or angry have you been? (2) Have you been sad, disappointed or angry because of your feelings?") rated on a 7-point Likert scale (ie, a score of $\geq 3$ indicating high reactivity) or by the interviewer-rated Comprehensive Assessment of At-Risk Mental State subscale [80] rated on a 7-point Likert scale (ie, with a rating of $\geq 3$ indicating high reactivity)

- Reduced positive affect (ie, a mean positive affect score below 3.19 for men and 3.05 for women based on normative scores from a representative sample of the German population [82]) or increased negative affect (ie, a mean negative affect score above 1.81 for men and 1.75 for women [82]) assessed using the Positive Affect and Negative Affect Scale [83]

- Willingness to participate in the EMIcompass intervention

- Ability to provide written informed consent (or consent by parents in the case of minors)

\section{Exclusion criteria}

- A primary diagnosis of alcohol or substance abuse or dependence, assessed using the Structured Clinical Interview for DSM-5 [79]

- Evidence that symptoms are precipitated by an organic disease

- Insufficient command of German so that the intervention cannot be followed, and outcomes cannot be reasonably assessed in German

- Diagnosis of a learning disability according to case records

- Current suicidal ideation (indicated by a score $>4$ in the Comprehensive Assessment of At-Risk Mental State [80]) 
Table 1. Inclusion criteria and transdiagnostic sample characteristics based on a modified version of the clinical staging model by Hartmann et al [16].

\begin{tabular}{ll}
\hline Stage and criteria & Measure
\end{tabular}

1a (distressed individuals)

- Psychological distress $\left(\mathrm{K} 10^{\mathrm{a}}\right.$ score $\left.\geq 20\right)$ but not fulfilling criteria of stage $1 \mathrm{~b}$ or 2

- $\mathrm{K} 10$

\section{1b (CHARMS $\left.{ }^{\mathbf{b}}\right)$}

Psychosis trait vulnerability

- First degree relative with psychosis and $\mathrm{SOFAS}^{\mathrm{c}}<50$ in the last 12 months or

- Family risk

- Or SOFAS 30\% below the past level

- $\quad$ SOFAS

Psychosis trait vulnerability

- Schizotypal personality and SOFAS $<50$ in the last 12 months or

- Or SOFAS 30\% below the past level

- $\quad$ SCID II ${ }^{\mathrm{d}}$

- $\quad$ SOFAS

Bipolar trait vulnerability

- Depressed mood or diminished interest or pleasure for at least 1 week as well as two additional criteria of depression: weight loss, sleep disorder, psychomotor disturbances, loss of energy, feelings of worthlessness or guilt, diminished ability to think or concentrate or indecisiveness, suicidality

- And mood swings for at least 6 months in the lifetime (not symptom-free for a longer period than 2 months consecutively) and at least three symptoms: decreased need for sleep, increased energy, inflated self-esteem or grandiosity, increase in goal-directed activity, restlessness, increased talkativeness, unusual ideas, risky behavior, inappropriate humor (does not have to equal loss of function!)

- Or first degree relative with bipolar disorder

\section{Attenuated psychotic symptoms}

- $\quad$ CAARMS ${ }^{\mathrm{f}}$ global rating score of 3-6 and frequency of 3-6 on the subscales: unusual thought content, nonbizarre ideas, perceptual abnormalities, disorganized speech

- Or global rating score of 6 and frequency of 3 on the subscales: unusual thought content, nonbizarre ideas, perceptual abnormalities, disorganized speech

\section{Attenuated hypomanic symptoms}

- Elevated, expansive or unusually irritable mood on at least 2 consecutive days

- And 2 (or in case of only irritable mood 3) additional criteria: inflated self-esteem or grandiosity, decreased need for sleep, increased talkativeness, flight of ideas or subjective experience that thoughts are racing, distractibility, increase in goal-directed activity or psychomotor agitation, unusual ideas, increased involvement in activities that are pleasurable in short time but have a high potential for long-term damage

- For a duration of 3 days maximum if 3 or more (or in case of only irritable mood 4 or more) additional criteria are met and there are functional disturbances or others notice the mood or functional disturbances

- For a duration of 6 days maximum if 3 or more (or in case of only irritable mood 4 or more) additional criteria are met or there are functional disturbances or others notice the mood or functional disturbances

- Exclusion: hospitalization, severe impairment in social or professional functioning, no psychotic elements

\section{Moderate (attenuated) depression}

- Mild or moderate depression (current or lifetime), that is, at least 1 cardinal symptom, 5 additional symptoms

- $\quad \operatorname{SCID}-5^{\mathrm{e}}$

- Family risk

- $\quad$ And HAM-D ${ }^{\mathrm{g}}>17$ (cutoff)

\section{BLIPS $^{\text {h }}$}

- Global rating of 6 on the subscales: unusual thought content or nonbizarre ideas

- Or global rating of 5 or 6 on the subscale perceptual abnormalities

- And/or global rating of 6 on the subscale disorganized speech present for less than a week

- And frequency of 4-6 on all above mentioned scales 


\begin{tabular}{|c|c|}
\hline Stage and criteria & Measure \\
\hline 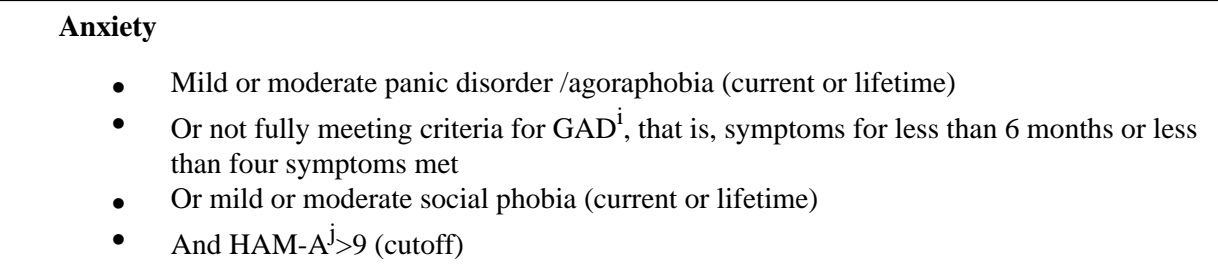 & $\begin{array}{ll}\text { - } & \text { SCID-5 } \\
\text { - } & \text { HAM-A }\end{array}$ \\
\hline \multicolumn{2}{|l|}{2 (first treated episode) } \\
\hline Psychosis & CAARMS \\
\hline Severe major depression (current or lifetime) & SCID-5 \\
\hline Mania or hypomania & SCID-5 \\
\hline Severe anxiety disorder (current or lifetime); eg, agoraphobia, GAD & SCID-5 \\
\hline
\end{tabular}

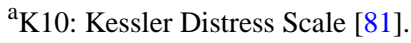

${ }^{\mathrm{b}}$ CHARMS: Clinical High At-Risk Mental State.

${ }^{\mathrm{c}}$ SOFAS: Social and Occupational Functioning Assessment Scale [84].

${ }^{\mathrm{d}}$ SCID II: Structured Clinical Interview for DSM-IV Axis II Personality Disorders,

e SCID-5: Structured Clinical Interview for Diagnostic and Statistical Manual of Mental Disorders, fifth edition (DSM-5) [79].

${ }^{\mathrm{f}}$ CAARMS: Comprehensive Assessment of At-Risk Mental State [80].

${ }^{g}$ HAM-D: Hamilton Depression Rating Scale [85].

${ }^{\mathrm{h}}$ BLIPS: brief limited intermittent psychotic symptoms.

${ }^{\mathrm{i}} \mathrm{GAD}$ : Generalized Anxiety Disorder.

${ }^{j}$ HAM-A: Hamilton Anxiety Rating Scale [86].

\section{Interventions}

\section{Control Condition: TAU}

Participants allocated to the TAU control condition will continue to receive all the treatment they received before the start of the study. This will include good standard care delivered according to local and national service guidelines and protocols by their general practitioner, psychiatrist, and other providers of (mental) health care. Service contacts will be assessed for the duration of the trial using the Client Service Receipt Inventory [87] to monitor variation in the delivery of, and engagement with, mental health services.

\section{Experimental Condition: EMIcompass Intervention Plus TAU}

The EMIcompass intervention will be delivered by trained psychologists within a 6-week period in addition to TAU to individuals allocated to the experimental condition. TAU consists of all the treatment individuals received before inclusion in the study, including their general practitioner, psychiatrist, and clinical psychologist, except for treatment using elements of third-wave CBT. The manualized EMIcompass intervention consists of four biweekly sessions (three training sessions and one review session) with a duration of 45-60 minutes administered face-to-face or using a certified and encrypted video conferencing system and a 6-week compassion-focused EMI. An optional on-demand session will be offered if participants are unable to complete tasks between sessions or report acute psychological distress so that a scheduled session cannot be followed as per the manual. The EMI, which translates the training from the intervention sessions into individuals' daily lives, will be administered through a smartphone-based app (movisensXS, movisens $\mathrm{GmbH}$ ) running on dedicated study smartphones. The first three sessions are based on elements of compassion-focused therapy [68]. In line with our pilot study [53], compassion-focused therapy principles and techniques are introduced in these guided sessions. The first session aims to familiarize the participants with the app offering EMI. Further, practical tasks to activate the soothing system, as a key emotion regulation system in compassion-focused therapy, are presented and trained together with the psychologist, as described elsewhere [88]. Face-to-face sessions also offer the opportunity to reflect on the progress and problems participants face with EMI. In the last session, progress with all tasks will be reviewed and subjective improvement in, compliance and satisfaction, and acceptance of the EMIcompass intervention will be assessed.

The app will offer EMI tasks according to three types of delivery schemes: (1) enhancing, (2) consolidating, and (3) interactive EMI tasks that aim for ecological translation of therapeutic principles and techniques to daily life. Participants will be asked to complete one enhancing task per week, practicing new compassion-focused tasks such as self-compassionate writing, experiencing emotions as a wave, and discovering their own compassionate self. Furthermore, participants will be offered consolidating tasks covering components of enhancing tasks from previous days. The components of consolidating tasks will be extended each time an enhancing task has been presented until all components are covered. In addition, participants will be offered to complete a brief EMA of momentary stress, affective disturbance, and threat anticipation six times per day, 3 days per week. On the basis of these EMAs, interactive tasks will be offered if participants score high on momentary stress or negative affect. The threshold for triggering interactive tasks 
will be either high momentary negative affect operationalized as a score of 4 or higher (on a 7-point Likert scale ranging from 1-7) on items of established and validated EMA measures of negative affect (Textbox 2) or high momentary stress based on items of established and validated measures of EMA of event-related, activity-related, or social stress (ie, a score $<0$ on a bipolar scale ranging from -3 to 3 ).

Participants will be instructed in detail in the semantic meaning of the 7-point Likert and bipolar scales and encouraged to carefully observe moment-to-moment variation in, and make use of the full range when rating, these scales on EMA items that have been previously used and validated to measure moment-to-moment variation in stress or negative affect. Given that a crucial element of compassion-focused therapy is for individuals to use compassionate imagery in moments of high stress or negative affect, these interactive tasks reflect an important component of the EMIcompass intervention. Participants can decline the EMI tasks in each delivery scheme. After completing the intervention period, participants will return the study devices and will no longer have access to the app. 
Textbox 2. Ecological momentary assessment domains and measures.

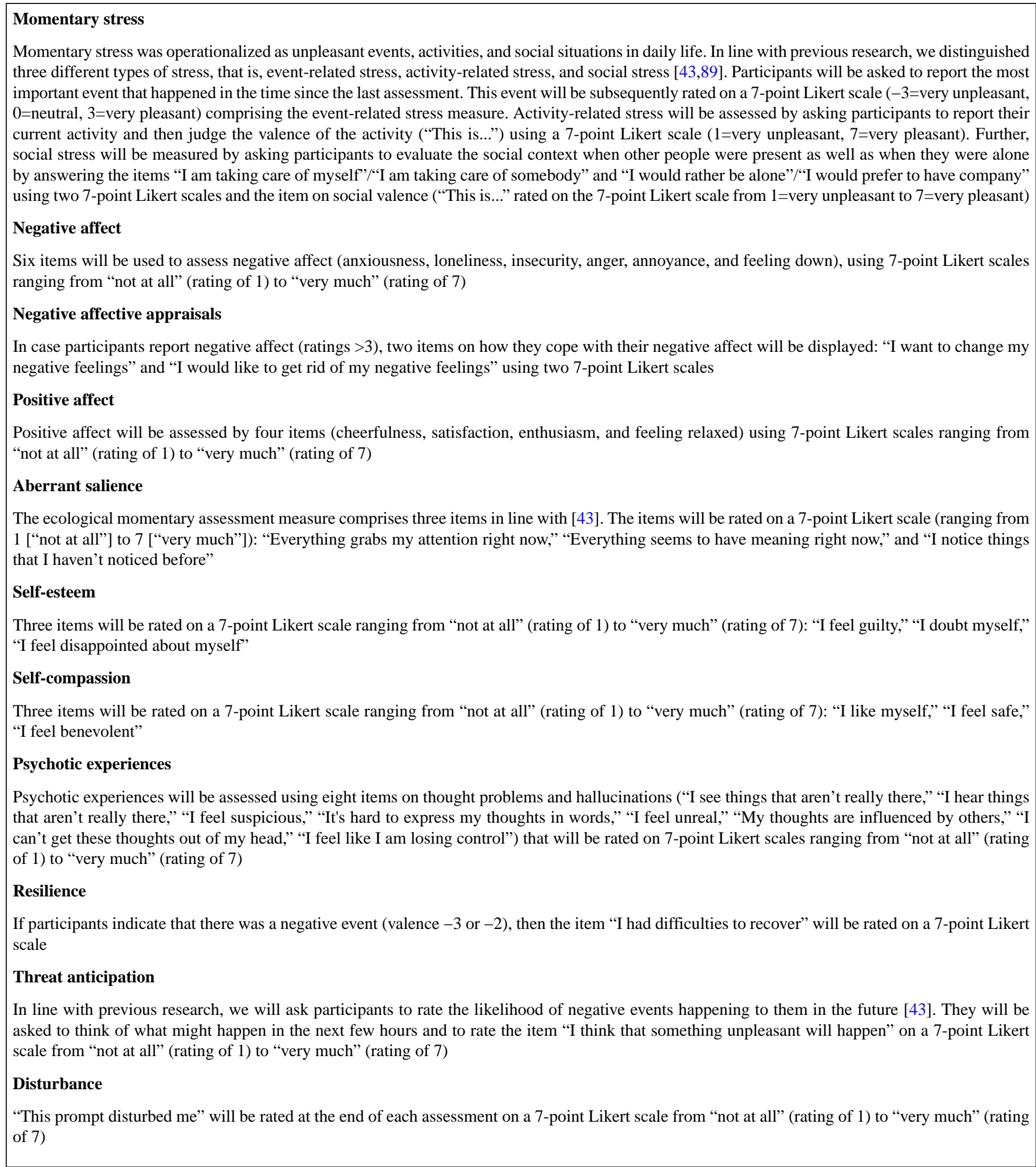

\section{Clinical Feasibility, Acceptability, Treatment Adherence, and Intervention Fidelity}

Clinical feasibility will be assessed in relation to the trial methodology and the delivery of the EMIcompass intervention to youth with early mental health problems. The feasibility of the trial methodology will be assessed based on the following criteria: (1) successful recruitment of at least 96 participants during the study period; (2) assessment of inclusion criteria in
$95 \%$ of potential participants after obtaining written consent; (3) successful randomization of at least 92 participants after completion of eligibility and baseline assessment; and (4) a retention rate of at least $85 \%$ for assessment of outcomes at least at one of the two time points at postintervention and 4-week follow-up. In addition, the following criteria will be used for establishing the feasibility of delivering the EMIcompass intervention, including its acceptability, intervention adherence, and intervention fidelity: (1) satisfaction with the EMIcompass 
intervention in general, ease of use, accessibility and comprehensiveness of various components of the intervention in a debriefing questionnaire [30,90], and the subjective quality of EMIcompass using the mobile application rating scale [91]; (2) compliance with, and adherence to, the EMIcompass intervention protocol based on a satisfactory level of session attendance, an adherence checklist covering all core components [29,30,92], and adherence to EMI tasks (ie, mean number of consolidating/interactive EMI tasks completed per week); and (3) fidelity to the EMIcompass intervention protocol based on independent ratings of a random selection of audio recordings of three face-to-face sessions, including fidelity to session protocol (ie, independent rating of core components delivered by trained psychologist), ability to model and embody the spirit of compassion, and the use of microskills in compassion-focused therapy assessed by the Compassion Focused Therapy-Therapist Competence Rating Scale [93].

\section{Candidate Mechanisms and Outcomes}

\section{Overview}

After obtaining written informed consent, all eligible participants will be assessed on candidate mechanisms and outcomes before randomization (baseline, $\mathrm{t}_{0}$ ), after the 6-week intervention period (postintervention, $\mathrm{t}_{1}$ ) and after a 4-week follow-up period (follow-up, $\mathrm{t}_{2}$ ) by blinded assessors (Figure 1 and Multimedia Appendix 1). Research Electronic Data Capture (REDCap) [94], a secure, web-based software platform hosted at the CIMH servers, will be used for data collection.

\section{Primary Candidate Mechanism}

The primary candidate mechanism is a reduction in stress reactivity acquired by EMA from baseline to postintervention for the experimental condition compared with the control condition. EMA will include eight assessments per day, scheduled at random within set blocks of time, for 6 consecutive days at baseline, postintervention, and follow-up [43,95]. Momentary stress will be assessed using established and validated EMA measures of event-related stress, activity-related stress, and social stress (Textbox 2) [43,89]. We will compute a composite momentary stress measure (ie, the mean score of event-related, activity-related, and social stress) in line with the literature [52,96,97] and the EMIcompass pilot study [53]. Negative affect will be assessed using an established and validated EMA measure of negative affect [43]. Stress reactivity as the primary candidate mechanism will be computed in linear mixed models with composite momentary stress as the independent variable and negative affect as the outcome variable $[43,89,95]$.

\section{Secondary Candidate Mechanisms}

Secondary candidate mechanisms (Multimedia Appendix 1 and Textbox 2) measured using EMA include threat anticipation, negative affective appraisals, emotional resilience to stress (operationalized as attenuated recovery in positive affect in response to minor stressors), and elevated stress reactivity (ie, increased negative affect) in response to event-related, activity-related, and social stress using subscale scores of the EMA stress measure. Threat anticipation will be additionally

https://www.researchprotocols.org/2021/12/e27462 assessed using the Threat Anticipation Measure [62], asking participants to estimate the future likelihood of a list of negative, neutral, and positive events happening to themselves and other people [61-63]. Interpersonal sensitivity will be assessed using the Interpersonal Sensitivity Measure [98] in addition to EMA. Resilience will be measured using the Connor-Davidson Resilience Scale [99] and the Resilience Scale [100]. Furthermore, the Self-Compassion Scale [101], the Fife Facet Mindfulness Questionnaire [102], and the Cognitive Emotion Regulation Questionnaire [103] will be used to assess self-compassion and emotion regulation. In addition, we will assess physiological markers of stress reactivity using a sensor for ambulatory ECG and actigraphy (movisens ECGmove4) during the 6-day EMA at baseline, postintervention, and at follow-up.

\section{Candidate Primary Outcome}

The candidate primary outcome of this exploratory RCT is psychological distress measured using the well-validated Kessler Psychological Distress Scale [81]. The 10 items are rated on a 1 (never) to 5 (always) Likert scale focusing on psychological distress in the last month. Strong psychometric properties have been reported with a reliability of Cronbach $\alpha>.90$ [81].

\section{Candidate Secondary Outcomes}

Secondary outcomes include primary (ie, psychotic, manic, anxiety, or depressive) symptoms and general psychopathology. These will be assessed using the following observer-rated measures: the Brief Psychiatric Rating Scale [104], including the Comprehensive Assessment of At-Risk Mental State [80], the Young Mania Rating Scale [105], the Hamilton Depression Rating Scale [85] and the Hamilton Anxiety Rating Scale [86]. On the basis of these measures, we will assess the transition to another clinical stage (according to a modified version of the clinical staging model by Hartmann et al [16]; see above). In addition, the following self-report measures will be used: the Brief Symptom Inventory [106], the Beck Depression Inventory [107], and the Prodromal Questionnaire [108]. Secondary outcomes further include quality of life measured using the WHO-Quality of Life assessment [109].

\section{Other Measures}

Other study parameters will include basic sociodemographic characteristics, familial risk factors for psychopathology, and other parameters (including age, sex, alcohol or substance use, and childhood trauma [110]). The Client Service Receipt Inventory [87] will be used to record patients' contacts with mental health services, monitor variation in the delivery of TAU, and model economic outcomes for a definitive trial. The Working Alliance Inventory [111,112] will be used to assess the relationship between practitioners and patients.

\section{Sample Size}

A formal sample size calculation is not essential for this exploratory trial, which primarily seeks to establish feasibility, effects on candidate mechanisms, and initial signals of efficacy. In planning, we aimed to determine the sample size in such a way as to establish the feasibility of the methodology for conducting an RCT and delivering the EMIcompass intervention to youth with early mental health problems and initial signals 
of the efficacy of EMIcompass in reducing psychological distress as a candidate primary outcome (see Statistical Analysis Plan [113] for further detail) as a basis for a future definitive trial. For the latter, previous studies of third-wave CBT [72,114], including compassion-focused interventions [68,77], suggest that these types of interventions may yield clinically meaningful reductions in psychological distress of moderate to large effect size. This is consistent with the initial findings from an uncontrolled phase I pilot study [53]. However, even if the effect size for the main effect of condition on psychological distress (primary outcome) in this exploratory RCT is small, a power simulation in the $\mathrm{R}$ environment indicated that a sample size of $\mathrm{N}=80$ participants $(40 / 40,50 \%$ experimental, $40 / 40,50 \%$ control condition) would be sufficient to detect a small effect size of 0.3 across the postintervention 4-week follow-up with a power of $81 \%$ when testing at $\alpha=.05$ for the effect of condition (experimental vs control condition) on psychological distress using linear mixed modeling, which will be tested using a Wald-type test of no difference between the two conditions across both time points against the two-sided alternative hypothesis that the conditions are, on average, different across the two follow-up time points (given the exploratory nature of this trial), while controlling for baseline psychological distress and group status. At the 4-week follow-up, we expect an attrition rate of $15 \%$, resulting in a loss to follow-up of approximately 6 individuals per condition on average (Figure 1). Therefore, we will randomize a total of 92 participants at baseline, leaving 80 participants at follow-up to detect a small effect size of 0.3 at this time point. This sample size is also sufficient to test the criteria for establishing feasibility. Simulation studies on power and accuracy for multilevel mediation models with continuous variables [115] and our recently completed multilevel moderated mediation analysis of EMA data [42] suggest very little bias in parameter estimates with samples of this size (and 40 repeated measures, on average, per participant).

\section{Randomization and Blinding}

Participants will be randomized at a 50:50 ratio to the experimental or control condition at the level of the individual participant after completion of the baseline assessment. Block randomization in blocks of four will be performed by an independent research assistant through a computer-generated sequence, with stratification for the three stages (ie, stages 1a, $1 \mathrm{~b}$, and 2). The assessors will be blind to the allocation of participants when assessing outcomes at postintervention and follow-up. Any data specific to the intervention group (eg, clinical feasibility) will be stored in a separate database. Breaks in masking will be documented, and another (blinded) researcher will repeat the assessment to maintain masking.

\section{Assessment of Safety}

Serious adverse events (SAEs) will be monitored throughout the entire study period and reported to the accredited Medical Ethics Review Committee, the Data Monitoring and Ethics Committee (DMEC), and, where required, the Trial Steering Committee (TSC). SAEs are any serious incidents that result in death, persistent or significant disability or incapacity that require hospitalization, or life-threatening situations. SAEs are not expected to occur as a result of the intervention. If there are doubts about safety or ethical concerns, the TSC will terminate the trial. The DMEC will advise on safety and ethical concerns, monitor evidence for harm by the intervention (eg, SAEs) in the experimental condition, and review whether these events are in line with expectations. If deemed necessary, the DMEC can recommend to the principal investigator (PI) and TSC for interim analyses to be conducted and the trial to be terminated prematurely.

\section{Statistical Analysis}

The primary objective of this exploratory RCT is to establish the feasibility of the trial methodology and intervention delivery and initial signals of efficacy on the candidate primary outcome (ie, psychological distress) as a basis for a future definitive trial. In addition, this trial seeks to obtain parameter estimates $(95 \%$ CI) for the effects on primary and secondary candidate mechanisms and candidate secondary outcomes. A detailed Statistical Analysis Plan [113] has been agreed with the DMEC and the TSC and has been preregistered and published on the Open Science Framework. It was registered while collecting the data before study completion and accessing the locked database. Descriptive statistics will be used, and CIs will be constructed as appropriate to compute basic sample characteristics and address the primary aim of establishing the feasibility of the trial methodology and intervention delivery based on the criteria described above and in further detail in the Statistical Analysis Plan using three categories (in line with a traffic light system): (1) feasibility fully established (green), (2) feasibility established, but study procedures need to be modified (yellow), and (3) feasibility not established (red) [113]. The analysis of candidate mechanisms and initial signals of efficacy has been described in detail in the Statistical Analysis Plan [113] and will be an intention-to-treat analysis or an available case analysis following intention-to-treat principles, with data from all participants entered into the analysis, including those who have low adherence to or who will drop out from the intervention. We will make every effort to assess all participants at postintervention and 4-week follow-up. Linear mixed modeling in Stata 16 will be used to compare candidate mechanisms and outcomes between experimental and control conditions at postintervention and 4-week follow-up. The primary candidate outcome of psychological distress measured at postintervention and 4-week follow-up will be entered as the dependent variable and psychological distress measured at baseline, group status (3-level factor), time (2-level factor), and condition (2-level factor) as independent variables. The main effect of condition on psychological distress will be parameterized so that it reflects the difference between the two conditions at the two follow-up time points (ie, postintervention and 4-week follow-up), which will be tested (at $\alpha=.05$ ) by a Wald-type test with $\mathrm{df}=1$, which tests the joint null hypothesis of no difference at both follow-up time points against the alternative hypothesis that there is, on average, a difference across the two follow-up time points. In addition, given the exploratory nature of this trial, with the main goal of establishing feasibility and obtaining parameter estimates for a future definitive RCT, 95\% CI for the two time-specific contrasts of a timexcondition interaction term will be inspected to obtain estimates for the differences across conditions at each of the 
two time points, with a time $\times$ condition interaction and a baseline psychological distress $\times$ time interaction added as independent variables to the previous model. Within-subject clustering of repeated measures (postintervention and 4-week follow-up) will be taken into account by including a level-2 random intercept and allowing the models' level-1 residuals to be correlated with a completely unstructured error variance-covariance matrix. The model will be fitted using restricted maximum likelihood estimation. The analysis of secondary candidate outcomes and primary and secondary candidate mechanisms will, in principle, follow the same steps, focusing on $95 \%$ CIs (rather than P values at $\alpha<.05$ ). Multilevel moderated mediation analysis of EMA data will be used to explore whether the effects of condition on primary (ie, psychotic, manic, anxiety, or depressive) symptoms are mediated via stress reactivity, threat anticipation, negative affective appraisals, and interpersonal sensitivity [42]. As participants will be randomly assigned to experimental and control conditions, no differences across conditions are expected in other study parameters (sociodemographic characteristics, alcohol or substance use, and childhood trauma). No statistical tests will be performed on these study parameters at baseline.

\section{Results}

\section{Overview}

The trial is ongoing. It started recruitment on July 15, 2019, and the first enrollment was conducted in August 2019. We are currently working with trial protocol version 5 (June 24, 2020). The last changes to the protocol were related to adaptations because of the COVID-19 pandemic, such as introducing the option of using video conferencing systems. As of May 2021, enrollment and randomization were completed ( $\mathrm{n}=92$ participants). Assessment of outcomes at postintervention and follow-up is still ongoing, with the last assessment for the last participant being scheduled for August 2021. Data will then be entered, checked, and the database locked (by September 2021). We expect results to be published in 2022.

\section{Research Governance}

The CIMH is the trial sponsor. The study has received ethical approval by the local ethics committee (EC) of the Medical Faculty Mannheim, Heidelberg University (2017-602N-MA). Amendments to the study protocol will be submitted to the EC and sent to the DMEC, TSC, and study sponsor. The trial is registered at the clinical trial register, and changes to the protocol will be updated. Deviations from the protocol will be documented in the study folder using a breach report form and will be reported to the TSC. The trial does not involve the collection or storage of biological samples. All data will be handled confidentially and will be coded using a number according to the order of study entry. Data will be securely stored in line with the European General Data Protection Regulation. Personal data will be kept separately from pseudonymized data. The PI has overall responsibility for the trial. The trial research team will meet regularly and will be chaired by the PI. It will manage the day-to-day running of the study, monitor the progress of the trial (ie, recruitment and assessment), and oversee the preparation of presentations and reports to EC, TSC, and DMEC. The TSC will meet biannually and provide independent overall supervision, monitor the progress of the trial (eg, recruitment, data completion rates, and adherence to the protocol), and approve the protocol and any amendments. The DMEC will meet at least once per year, advise on ethical or safety concerns, monitor SAEs and other evidence of intervention harm and whether this is in line with expectations. If deemed necessary, the DMEC can recommend that the PI and TSC are granted access to all trial data, to perform interim analyses and to terminate the trial prematurely.

\section{Discussion}

Transdiagnostic mechanisms implicated in the development of severe mental disorders are important targets for prevention and early intervention. Ecological translation of compassion-focused intervention components to individuals' daily lives through an EMI offers new avenues for tangible prevention strategies delivering real-world and real-time interventions that are easily accessible by youth [36]. Findings from a recent, nationally representative survey suggest that psychological distress, social isolation, lack of company, and worrying during the COVID-19 pandemic were highly prevalent in youth and, interestingly, associated with the current use of and a positive attitude toward digital interventions [33]. EMIs are also amenable to enhancing access to mental health services for youth depending on their needs and preferences, for instance, by delivering low-threshold interventions by frontline mental health staff [116-118] as a component that can be rolled out across adolescent and adult mental health services and link in with what is urgently needed, that is, a wider youth mental health reform that aims to provide seamless coverage of mental health care with smooth transitions from adolescence to mature adulthood at an age of approximately 25 years [20]. Furthermore, EMIs allow for investigating the strength of the evidence in support of several causal criteria (ie, association, temporality, sole plausibility, and ecological validity) as part of the ecological interventionist causal model approach that targets candidate underlying psychological mechanisms in daily life to achieve sustainable change under real-world conditions [27]. However, robust, trial-based evidence on EMIs and other mHealth interventions remain very limited $[26,27,29,36,116,119]$. A key next step is to examine the efficacy of youth-friendly, accessible, interactive, real-time interventions targeting candidate mechanisms underlying the transdiagnostic phenotype of psychosis, mania, depression and anxiety and thereby, help preventing adverse outcomes later in life. While, in the current study, we use EMA items that have been previously used and validated to measure moment-to-moment variation in stress/negative affect, with considerable within-person variability having been observed for these items in several EMA studies [43,89,120], inter-individual differences in within-person variability as well as general response tendencies may influence the number of triggered EMI tasks and hence, further research is needed to optimize and personalize the assignment of EMI components, eg, by using methods of artificial intelligence, recurrent neural networks (RNNs) in particular [121]. For example, we currently aim to apply recurrent neural networks in an ongoing study of personalized digital mental health promotion and prevention in 
youth [33]. In addition, clinical staging models of severe mental disorders require further scrutiny, including heterogeneity in phenomenology, course, and outcome within individual stages $[5,122,123]$.

The present exploratory RCT is the first to establish feasibility, evidence on underlying mechanisms, and preliminary signals of efficacy of a compassion-focused, hybrid EMI for reducing stress reactivity (EMIcompass) in youth at different clinical stages. Preliminary evidence from a pilot study of the
EMIcompass intervention in help-seeking youth showed reductions in clinical symptoms and stress reactivity [53]. If this exploratory trial is successful, a confirmatory RCT will be warranted. Overall, our approach has a scalable potential to prevent the transition of early mental health problems to severe and enduring mental disorders not only in individuals at risk of developing psychosis but transdiagnostically and across clinical stages and, thereby, significantly advance preventive interventions in youth mental health provision.

\section{Acknowledgments}

This work is funded by a German Research Foundation project grant (\#389626655) and German Research Foundation Heisenberg professorship (\#389624707) to UR. The sponsor and funding agency do not have any role in the trial design, data collection, statistical analysis, interpretation of data, writing of the manuscript, or the decision to submit reports for publication. AML is supported by German Federal Ministry of Education and Research (BMBF, grant 01EF1803A) Ministry of Science, Research and the Arts of the State of Baden-Wuerttemberg, Germany (MWK, grant 42-5400/136/1); Ministry of Science, Research and the Arts of the State of Baden-Wuerttemberg, Germany (MWK, grant 42-04HV.MED(16)/16/1); and Ministry of Science, Research and the Arts of the State of Baden-Wuerttemberg, Germany (MWK, grant 42-04HV.MED(16)/27/1). The authors are indebted to all individuals who participated, past and present, in the EMIcompass study and are essential for its successful completion. The authors are grateful to Professor Stefan Priebe, Professor Stefan Wellek, Dr Jan R Böhnke, Professor Nicolas Rüsch, Dr Thomas Vaessen, Professor Maria Blettner, Professor Sebastian von Peter, and Professor Georg Schomerus for their membership in the TSC and DMEC, respectively. The authors also thank all trained psychologists (Isabell Paetzold, Dr. Sebastian Butz, and Leonie Schültke) and research assistants.

\section{Authors' Contributions}

UR designed the study, is the PI, and has managerial responsibility for the successful completion of the study. JB is the trial statistician. BB provides supervision for the trained psychologists who deliver the intervention. AS, UR, CR, and IP drafted the manuscript. All authors were involved in writing, reading, and approving the final manuscript.

\section{Conflicts of Interest}

None declared.

\section{Multimedia Appendix 1}

Standard Protocol Items: Recommendations for International Trials (SPIRIT) figure.

[DOCX File , 28 KB-Multimedia Appendix 1]

\section{References}

1. Kessler RC, Berglund P, Demler O, Jin R, Merikangas KR, Walters EE. Lifetime prevalence and age-of-onset distributions of DSM-IV disorders in the National Comorbidity Survey Replication. Arch Gen Psychiatry 2005 Jun;62(6):593-602. [doi: 10.1001/archpsyc.62.6.593] [Medline: 15939837]

2. van Os J, Reininghaus U. Psychosis as a transdiagnostic and extended phenotype in the general population. World Psychiatry 2016 Jun;15(2):118-124 [FREE Full text] [doi: 10.1002/wps.20310] [Medline: 27265696]

3. McGorry P, van Os J. Redeeming diagnosis in psychiatry: timing versus specificity. Lancet 2013 Jan 26;381(9863):343-345. [doi: 10.1016/S0140-6736(12)61268-9] [Medline: 23351805]

4. van Os J. The dynamics of subthreshold psychopathology: implications for diagnosis and treatment. Am J Psychiatry 2013 Jul;170(7):695-698. [doi: 10.1176/appi.ajp.2013.13040474] [Medline: 23820827]

5. Reininghaus U, Priebe S, Bentall RP. Testing the psychopathology of psychosis: evidence for a general psychosis dimension. Schizophr Bull 2013 Jul;39(4):884-895 [FREE Full text] [doi: 10.1093/schbul/sbr182] [Medline: 22258881]

6. Reininghaus U, Böhnke JR, Hosang G, Farmer A, Burns T, McGuffin P, et al. Evaluation of the validity and utility of a transdiagnostic psychosis dimension encompassing schizophrenia and bipolar disorder. Br J Psychiatry 2016 Aug;209(2):107-113. [doi: 10.1192/bjp.bp.115.167882] [Medline: 26989099]

7. Quattrone D, Di Forti M, Gayer-Anderson C, Ferraro L, Jongsma HE, Tripoli G, EU-GEI WP2 Group, et al. Transdiagnostic dimensions of psychopathology at first episode psychosis: findings from the multinational EU-GEI study. Psychol Med 2019 Jun;49(8):1378-1391 [FREE Full text] [doi: 10.1017/S0033291718002131] [Medline: 30282569] 
8. Lahey BB, Applegate B, Hakes JK, Zald DH, Hariri AR, Rathouz PJ. Is there a general factor of prevalent psychopathology during adulthood? J Abnorm Psychol 2012 Nov;121(4):971-977 [FREE Full text] [doi: 10.1037/a0028355] [Medline: $\underline{22845652]}$

9. Lahey BB, Van Hulle CA, Singh AL, Waldman ID, Rathouz PJ. Higher-order genetic and environmental structure of prevalent forms of child and adolescent psychopathology. Arch Gen Psychiatry 2011 Feb;68(2):181-189 [FREE Full text] [doi: 10.1001/archgenpsychiatry.2010.192] [Medline: 21300945]

10. Caspi A, Houts RM, Belsky DW, Goldman-Mellor SJ, Harrington H, Israel S, et al. The p factor: one general psychopathology factor in the structure of psychiatric disorders? Clin Psychol Sci 2014 Mar;2(2):119-137 [FREE Full text] [doi: 10.1177/2167702613497473] [Medline: 25360393]

11. Ruggero CJ, Kotov R, Hopwood CJ, First M, Clark LA, Skodol AE, et al. Integrating the Hierarchical Taxonomy of Psychopathology (HiTOP) into clinical practice. J Consult Clin Psychol 2019 Dec;87(12):1069-1084 [FREE Full text] [doi: 10.1037/ccp0000452] [Medline: $\underline{31724426]}$

12. Kotov R, Krueger RF, Watson D, Achenbach TM, Althoff RR, Bagby RM, et al. The Hierarchical Taxonomy of Psychopathology (HiTOP): a dimensional alternative to traditional nosologies. J Abnorm Psychol 2017 May;126(4):454-477. [doi: 10.1037/abn0000258] [Medline: 28333488]

13. Kotov R, Jonas KG, Carpenter WT, Dretsch MN, Eaton NR, Forbes MK, HiTOP Utility Workgroup. Validity and utility of Hierarchical Taxonomy of Psychopathology (HiTOP): I. Psychosis superspectrum. World Psychiatry 2020 Jun;19(2):151-172 [FREE Full text] [doi: 10.1002/wps.20730] [Medline: 32394571]

14. Conway CC, Forbes MK, Forbush KT, Fried EI, Hallquist MN, Kotov R, et al. A hierarchical taxonomy of psychopathology can transform mental health research. Perspect Psychol Sci 2019 May;14(3):419-436 [FREE Full text] [doi: 10.1177/1745691618810696] [Medline: $\underline{\text { 30844330] }}$

15. Hartmann JA, Nelson B, Ratheesh A, Treen D, McGorry PD. At-risk studies and clinical antecedents of psychosis, bipolar disorder and depression: a scoping review in the context of clinical staging. Psychol Med 2019 Jan;49(2):177-189. [doi: 10.1017/S0033291718001435] [Medline: 29860956]

16. Hartmann JA, Nelson B, Spooner R, Amminger GP, Chanen A, Davey CG, et al. Broad clinical high-risk mental state (CHARMS): methodology of a cohort study validating criteria for pluripotent risk. Early Interv Psychiatry 2019 Jun;13(3):379-386. [doi: 10.1111/eip.12483] [Medline: 28984077]

17. Shah JL, Scott J, McGorry PD, Cross SP, Keshavan MS, Nelson B, International Working Group on Transdiagnostic Clinical Staging in Youth Mental Health. Transdiagnostic clinical staging in youth mental health: a first international consensus statement. World Psychiatry 2020 Jun;19(2):233-242 [FREE Full text] [doi: 10.1002/wps.20745] [Medline: 32394576]

18. Iorfino F, Scott EM, Carpenter JS, Cross SP, Hermens DF, Killedar M, et al. Clinical stage transitions in persons aged 12 to 25 years presenting to early intervention mental health services with anxiety, mood, and psychotic disorders. JAMA Psychiatry 2019 Nov 01;76(11):1167-1175 [FREE Full text] [doi: 10.1001/jamapsychiatry.2019.2360] [Medline: 31461129]

19. Gore FM, Bloem PJ, Patton GC, Ferguson J, Joseph V, Coffey C, et al. Global burden of disease in young people aged 10-24 years: a systematic analysis. Lancet 2011 Jun 18;377(9783):2093-2102. [doi: 10.1016/S0140-6736(11)60512-6] [Medline: 21652063]

20. Malla A, Iyer S, McGorry P, Cannon M, Coughlan H, Singh S, et al. From early intervention in psychosis to youth mental health reform: a review of the evolution and transformation of mental health services for young people. Soc Psychiatry Psychiatr Epidemiol 2016 Mar;51(3):319-326. [doi: 10.1007/s00127-015-1165-4] [Medline: 26687237]

21. Wang PS, Berglund P, Olfson M, Pincus HA, Wells KB, Kessler RC. Failure and delay in initial treatment contact after first onset of mental disorders in the National Comorbidity Survey Replication. Arch Gen Psychiatry 2005 Jun;62(6):603-613. [doi: 10.1001/archpsyc.62.6.603] [Medline: 15939838]

22. Csikszentmihalyi M, Larson R. Validity and reliability of the experience-sampling method. J Nerv Ment Dis 1987 Sep;175(9):526-536. [doi: 10.1097/00005053-198709000-00004] [Medline: $\underline{\text { 3655778] }}$

23. Myin-Germeys I, Kasanova Z, Vaessen T, Vachon H, Kirtley O, Viechtbauer W, et al. Experience sampling methodology in mental health research: new insights and technical developments. World Psychiatry 2018 Jun;17(2):123-132 [FREE Full text] [doi: 10.1002/wps.20513] [Medline: 29856567]

24. Heron KE, Smyth JM. Ecological momentary interventions: incorporating mobile technology into psychosocial and health behaviour treatments. Br J Health Psychol 2010 Feb;15(Pt 1):1-39 [FREE Full text] [doi: 10.1348/135910709X466063] [Medline: 19646331]

25. Myin-Germeys I, Birchwood M, Kwapil T. From environment to therapy in psychosis: a real-world momentary assessment approach. Schizophr Bull 2011 Mar;37(2):244-247 [FREE Full text] [doi: 10.1093/schbul/sbq164] [Medline: 21224492]

26. Myin-Germeys I, Klippel A, Steinhart H, Reininghaus U. Ecological momentary interventions in psychiatry. Curr Opin Psychiatry 2016 Jul;29(4):258-263. [doi: 10.1097/YCO.0000000000000255] [Medline: 27153125]

27. Reininghaus U, Depp CA, Myin-Germeys I. Ecological interventionist causal models in psychosis: targeting psychological mechanisms in daily life. Schizophr Bull 2016 Mar;42(2):264-269 [FREE Full text] [doi: 10.1093/schbul/sbv193] [Medline: 26707864] 
28. Reininghaus U. [Ecological momentary interventions in psychiatry: the momentum for change in daily social context]. Psychiatr Prax 2018 Mar;45(2):59-61. [doi: 10.1055/s-0044-101986] [Medline: 29495051]

29. van Aubel E, Bakker JM, Batink T, Michielse S, Goossens L, Lange I, et al. Blended care in the treatment of subthreshold symptoms of depression and psychosis in emerging adults: a randomised controlled trial of Acceptance and Commitment Therapy in Daily-Life (ACT-DL). Behav Res Ther 2020 May;128:103592. [doi: 10.1016/j.brat.2020.103592] [Medline: $\underline{32146218]}$

30. Reininghaus U, Klippel A, Steinhart H, Vaessen T, van Nierop M, Viechtbauer W, et al. Efficacy of Acceptance and Commitment Therapy in Daily Life (ACT-DL) in early psychosis: study protocol for a multi-centre randomized controlled trial. Trials 2019 Dec 26;20(1):769 [FREE Full text] [doi: 10.1186/s13063-019-3912-4] [Medline: $\underline{31878966}$ ]

31. Nahum-Shani I, Smith SN, Spring BJ, Collins LM, Witkiewitz K, Tewari A, et al. Just-in-Time Adaptive Interventions (JITAIs) in mobile health: key components and design principles for ongoing health behavior support. Ann Behav Med 2018 May 18;52(6):446-462 [FREE Full text] [doi: 10.1007/s12160-016-9830-8] [Medline: 27663578]

32. Steinhart H, Myin-Germeys I, Reininghaus U. Translating treatment of mental health problems to daily life: a guide to the development of ecological momentary interventions. In: Palmier-Claus J, Haddock G, Varese F, editors. Experience Sampling in Mental Health Research. London, UK: Routledge; 2019:1-176.

33. Rauschenberg C, Schick A, Goetzl C, Roehr S, Riedel-Heller SG, Koppe G, et al. Social isolation, mental health, and use of digital interventions in youth during the COVID-19 pandemic: a nationally representative survey. Eur Psychiatry 2021 Mar 09;64(1):e20 [FREE Full text] [doi: 10.1192/j.eurpsy.2021.17] [Medline: 33686930]

34. Larsen ME, Huckvale K, Nicholas J, Torous J, Birrell L, Li E, et al. Using science to sell apps: evaluation of mental health app store quality claims. NPJ Digit Med 2019 Mar 22;2(1):18 [FREE Full text] [doi: 10.1038/s41746-019-0093-1] [Medline: $\underline{31304366}$ ]

35. Mercurio M, Larsen M, Wisniewski H, Henson P, Lagan S, Torous J. Longitudinal trends in the quality, effectiveness and attributes of highly rated smartphone health apps. Evid Based Ment Health 2020 Aug;23(3):107-111 [FREE Full text] [doi: 10.1136/ebmental-2019-300137] [Medline: 32312794]

36. Rauschenberg C, Schick A, Hirjak D, Seidler A, Paetzold I, Apfelbacher C, et al. Evidence synthesis of digital interventions to mitigate the negative impact of the COVID-19 pandemic on public mental health: rapid meta-review. J Med Internet Res 2021 Mar 10;23(3):e23365 [FREE Full text] [doi: 10.2196/23365] [Medline: 33606657]

37. Versluis A, Verkuil B, Spinhoven P, van der Ploeg MM, Brosschot JF. Changing mental health and positive psychological well-being using ecological momentary interventions: a systematic review and meta-analysis. J Med Internet Res 2016 Jun 27;18(6):e152 [FREE Full text] [doi: 10.2196/jmir.5642] [Medline: 27349305]

38. Granholm E, Ben-Zeev D, Link PC, Bradshaw KR, Holden JL. Mobile Assessment and Treatment for Schizophrenia (MATS): a pilot trial of an interactive text-messaging intervention for medication adherence, socialization, and auditory hallucinations. Schizophr Bull 2012 May;38(3):414-425 [FREE Full text] [doi: 10.1093/schbul/sbr155] [Medline: 22080492]

39. Ben-Zeev D, Kaiser SM, Brenner CJ, Begale M, Duffecy J, Mohr DC. Development and usability testing of FOCUS: a smartphone system for self-management of schizophrenia. Psychiatr Rehabil J 2013 Dec;36(4):289-296 [FREE Full text] [doi: 10.1037/prj0000019] [Medline: 24015913]

40. Erbe D, Eichert H, Riper H, Ebert DD. Blending face-to-face and internet-based interventions for the treatment of mental disorders in adults: systematic review. J Med Internet Res 2017 Sep 15;19(9):e306 [FREE Full text] [doi: 10.2196/jmir.6588] [Medline: 28916506]

41. Wright JH, Owen JJ, Richards D, Eells TD, Richardson T, Brown GK, et al. Computer-assisted cognitive-behavior therapy for depression: a systematic review and meta-analysis. J Clin Psychiatry 2019 Mar 19;80(2):18r12188 [FREE Full text] [doi: 10.4088/JCP.18r12188] [Medline: 30900849]

42. Klippel A, Myin-Germeys I, Chavez-Baldini U, Preacher KJ, Kempton M, Valmaggia L, et al. Modeling the interplay between psychological processes and adverse, stressful contexts and experiences in pathways to psychosis: an experience sampling study. Schizophr Bull 2017 Mar 01;43(2):302-315 [FREE Full text] [doi: 10.1093/schbul/sbw185] [Medline: 28204708]

43. Reininghaus U, Kempton MJ, Valmaggia L, Craig TK, Garety P, Onyejiaka A, et al. Stress sensitivity, aberrant salience, and threat anticipation in early psychosis: an experience sampling study. Schizophr Bull 2016 May;42(3):712-722 [FREE Full text] [doi: 10.1093/schbul/sbv190] [Medline: 26834027]

44. Reininghaus U, Gayer-Anderson C, Valmaggia L, Kempton MJ, Calem M, Onyejiaka A, et al. Psychological processes underlying the association between childhood trauma and psychosis in daily life: an experience sampling study. Psychol Med 2016 Oct;46(13):2799-2813 [FREE Full text] [doi: 10.1017/S003329171600146X] [Medline: 27400863]

45. Myin-Germeys I, van Os J. Stress-reactivity in psychosis: evidence for an affective pathway to psychosis. Clin Psychol Rev 2007 May;27(4):409-424. [doi: 10.1016/j.cpr.2006.09.005] [Medline: 17222489]

46. Collip D, Myin-Germeys I, Van Winkel R, van Os J. [Stress and psychosis: is sensitisation the underlying mechanism?]. Tijdschr Psychiatr 2009;51(8):559-567 [FREE Full text] [Medline: 19658068]

47. Lataster T, Myin-Germeys I, Derom C, Thiery E, van Os J. Evidence that self-reported psychotic experiences represent the transitory developmental expression of genetic liability to psychosis in the general population. Am J Med Genet B Neuropsychiatr Genet 2009 Dec 05;150B(8):1078-1084. [doi: 10.1002/ajmg.b.30933] [Medline: 19229852] 
48. Wichers M, Simons CJ, Kramer IM, Hartmann JA, Lothmann C, Myin-Germeys I, et al. Momentary assessment technology as a tool to help patients with depression help themselves. Acta Psychiatr Scand 2011 Oct;124(4):262-272. [doi: 10.1111/j.1600-0447.2011.01749.x] [Medline: 21838742]

49. Bender RE, Alloy LB. Life stress and kindling in bipolar disorder: review of the evidence and integration with emerging biopsychosocial theories. Clin Psychol Rev 2011 Apr;31(3):383-398 [FREE Full text] [doi: 10.1016/j.cpr.2011.01.004] [Medline: 21334286]

50. Harkness KL, Hayden EP, Lopez-Duran NL. Stress sensitivity and stress sensitization in psychopathology: an introduction to the special section. J Abnorm Psychol 2015 Feb;124(1):1-3. [doi: 10.1037/abn0000041] [Medline: 25688427]

51. Weiss RB, Stange JP, Boland EM, Black SK, LaBelle DR, Abramson LY, et al. Kindling of life stress in bipolar disorder: comparison of sensitization and autonomy models. J Abnorm Psychol 2015 Mar;124(1):4-16 [FREE Full text] [doi: 10.1037/abn0000014] [Medline: 25688428]

52. Rauschenberg C, van Os J, Goedhart M, Schieveld JN, Reininghaus U. Bullying victimization and stress sensitivity in help-seeking youth: findings from an experience sampling study. Eur Child Adolesc Psychiatry 2021 May 13;30(4):591-605 [FREE Full text] [doi: 10.1007/s00787-020-01540-5] [Medline: 32405792]

53. Rauschenberg C, Boecking B, Paetzold I, Schruers K, Schick A, van Amelsvoort T, et al. An ecological momentary compassion-focused intervention for enhancing resilience in help-seeking youth: a pilot study. PsyArXiv 2020 Sep:(forthcoming) [FREE Full text] [doi: 10.31234/osf.io/txhp7]

54. Rauschenberg C, van Os J, Cremers D, Goedhart M, Schieveld JN, Reininghaus U. Stress sensitivity as a putative mechanism linking childhood trauma and psychopathology in youth's daily life. Acta Psychiatr Scand 2017 Oct;136(4):373-388. [doi: 10.1111/acps.12775] [Medline: 28758672]

55. Bell V, Freeman D. A pilot trial of cognitive behavioural therapy for interpersonal sensitivity in individuals with persecutory delusions. J Behav Ther Exp Psychiatry 2014 Dec;45(4):441-446. [doi: 10.1016/j.jbtep.2014.06.001] [Medline: 24974215]

56. Masillo A, Day F, Laing J, Howes O, Fusar-Poli P, Byrne M, et al. Interpersonal sensitivity in the at-risk mental state for psychosis. Psychol Med 2012 Sep;42(9):1835-1845. [doi: 10.1017/S0033291711002996] [Medline: 22225783]

57. Wilhelm K, Boyce P, Brownhill S. The relationship between interpersonal sensitivity, anxiety disorders and major depression. J Affect Disord 2004 Apr;79(1-3):33-41. [doi: 10.1016/S0165-0327(02)00069-1] [Medline: 15023478]

58. Akiskal HS, Maser JD, Zeller PJ, Endicott J, Coryell W, Keller M, et al. Switching from 'unipolar' to bipolar II. An 11-year prospective study of clinical and temperamental predictors in 559 patients. Arch Gen Psychiatry 1995 Feb;52(2):114-123. [doi: 10.1001/archpsyc.1995.03950140032004] [Medline: 7848047]

59. Harb GC, Heimberg RG, Fresco DM, Schneier FR, Liebowitz MR. The psychometric properties of the Interpersonal Sensitivity Measure in social anxiety disorder. Behav Res Ther 2002 Aug;40(8):961-979. [doi: 10.1016/s0005-7967(01)00125-5] [Medline: 12186358]

60. Bentall RP, de Sousa P, Varese F, Wickham S, Sitko K, Haarmans M, et al. From adversity to psychosis: pathways and mechanisms from specific adversities to specific symptoms. Soc Psychiatry Psychiatr Epidemiol 2014 Jul;49(7):1011-1022. [doi: 10.1007/s00127-014-0914-0] [Medline: 24919446]

61. Bentall RP, Rowse G, Shryane N, Kinderman P, Howard R, Blackwood N, et al. The cognitive and affective structure of paranoid delusions: a transdiagnostic investigation of patients with schizophrenia spectrum disorders and depression. Arch Gen Psychiatry 2009 Mar;66(3):236-247. [doi: 10.1001/archgenpsychiatry.2009.1] [Medline: 19255373]

62. Corcoran R, Cummins S, Rowse G, Moore R, Blackwood N, Howard R, et al. Reasoning under uncertainty: heuristic judgments in patients with persecutory delusions or depression. Psychol Med 2006 Aug;36(8):1109-1118. [doi: 10.1017/S003329170600794X] [Medline: 16734944]

63. Freeman D, Dunn G, Fowler D, Bebbington P, Kuipers E, Emsley R, et al. Current paranoid thinking in patients with delusions: the presence of cognitive-affective biases. Schizophr Bull 2013 Nov;39(6):1281-1287 [FREE Full text] [doi: 10.1093/schbul/sbs145] [Medline: 23223342]

64. Clark DM, McManus F. Information processing in social phobia. Biol Psychiatry 2002 Jan 01;51(1):92-100. [doi: 10.1016/s0006-3223(01)01296-3] [Medline: 11801234]

65. Kaney S, Bowen-Jones K, Dewey M, Bentall RP. Two predictions about paranoid ideation: deluded, depressed and normal participants' subjective frequency and consensus judgments for positive, neutral and negative events. Br J Clin Psychol 1997 Sep;36(3):349-364. [doi: 10.1111/j.2044-8260.1997.tb01243.x] [Medline: 9309351]

66. Shevlin M, McElroy E, Bentall RP, Reininghaus U, Murphy J. The psychosis continuum: testing a bifactor model of psychosis in a general population sample. Schizophr Bull 2017 Jan;43(1):133-141 [FREE Full text] [doi: 10.1093/schbul/sbw067] [Medline: 27220965]

67. Gordon RS. An operational classification of disease prevention. In: Silverman J, editor. Preventing Mental Disorders. Rockville, MD: U.S. Department of Health and Human Services; 1987:107-109.

68. Gilbert P. Introducing compassion-focused therapy. Adv Psychiatr Treat 2009 May;15(3):199-208. [doi: 10.1192/apt.bp.107.005264]

69. Gilbert P. Compassion Focused Therapy: Distinctive Features. Oxfordshire England: Routledge; 2009.

70. Gilbert P. The origins and nature of compassion focused therapy. Br J Clin Psychol 2014 Mar;53(1):6-41. [doi: 10.1111/bjc. 12043] [Medline: 24588760] 
71. Kirby JN, Tellegen CL, Steindl SR. A meta-analysis of compassion-based interventions: current state of knowledge and future directions. Behav Ther 2017 Nov;48(6):778-792. [doi: 10.1016/j.beth.2017.06.003] [Medline: 29029675]

72. Tai S, Turkington D. The evolution of cognitive behavior therapy for schizophrenia: current practice and recent developments. Schizophr Bull 2009 Sep;35(5):865-873 [FREE Full text] [doi: 10.1093/schbul/sbp080] [Medline: 19661198]

73. MacBeth A, Gumley A. Exploring compassion: a meta-analysis of the association between self-compassion and psychopathology. Clin Psychol Rev 2012 Aug;32(6):545-552. [doi: 10.1016/j.cpr.2012.06.003] [Medline: 22796446]

74. Frostadottir AD, Dorjee D. Effects of Mindfulness Based Cognitive Therapy (MBCT) and Compassion Focused Therapy (CFT) on symptom change, mindfulness, self-compassion, and rumination in clients with depression, anxiety, and stress. Front Psychol 2019 May 17;10:1099 [FREE Full text] [doi: 10.3389/fpsyg.2019.01099] [Medline: 31164849]

75. Louise S, Fitzpatrick M, Strauss C, Rossell SL, Thomas N. Mindfulness- and acceptance-based interventions for psychosis: our current understanding and a meta-analysis. Schizophr Res 2018 Feb;192:57-63. [doi: 10.1016/j.schres.2017.05.023] [Medline: 28545945]

76. Spijkerman MP, Pots WT, Bohlmeijer ET. Effectiveness of online mindfulness-based interventions in improving mental health: a review and meta-analysis of randomised controlled trials. Clin Psychol Rev 2016 Apr;45:102-114 [FREE Full text] [doi: 10.1016/j.cpr.2016.03.009] [Medline: 27111302]

77. Lincoln TM, Hohenhaus F, Hartmann M. Can paranoid thoughts be reduced by targeting negative emotions and self-esteem? An experimental investigation of a brief compassion-focused intervention. Cogn Ther Res 2012 Aug 14;37(2):390-402. [doi: $10.1007 / \mathrm{s} 10608-012-9470-7]$

78. Pearson J, Naselaris T, Holmes EA, Kosslyn SM. Mental imagery: functional mechanisms and clinical applications. Trends Cogn Sci 2015 Oct;19(10):590-602 [FREE Full text] [doi: 10.1016/j.tics.2015.08.003] [Medline: 26412097]

79. First M, Williams J, Karg R, Spitzer R. The structured clinical interview for DSM-5®. American Psychiatric Association. URL: https://www.appi.org/products/structured-clinical-interview-for-dsm-5-scid-5 [accessed 2021-09-07]

80. Yung AR, Yuen HP, McGorry PD, Phillips LJ, Kelly D, Dell'Olio M, et al. Mapping the onset of psychosis: the comprehensive assessment of at-risk mental states. Aust N Z J Psychiatry 2005;39(11-12):964-971. [doi: 10.1080/j.1440-1614.2005.01714.X] [Medline: 16343296$]$

81. Kessler RC, Andrews G, Colpe LJ, Hiripi E, Mroczek DK, Normand SL, et al. Short screening scales to monitor population prevalences and trends in non-specific psychological distress. Psychol Med 2002 Aug;32(6):959-976. [doi: 10.1017/s0033291702006074] [Medline: 12214795]

82. Breyer B, Bluemke M. Deutsche Version der Positive and Negative Affect Schedule PANAS (GESIS Panel). Social Science Open Access Repository. 2016. URL: https://nbn-resolving.org/urn:nbn:de:0168-ssoar-65680-6 [accessed 2021-09-07]

83. Watson D, Clark LA, Tellegen A. Development and validation of brief measures of positive and negative affect: the PANAS scales. J Pers Soc Psychol 1988 Jun;54(6):1063-1070. [doi: 10.1037//0022-3514.54.6.1063] [Medline: $\underline{3397865]}$

84. Goldman HH, Skodol AE, Lave TR. Revising axis V for DSM-IV: a review of measures of social functioning. Am J Psychiatry 1992 Sep;149(9):1148-1156. [doi: 10.1176/ajp.149.9.1148] [Medline: 1386964]

85. Hamilton M. A rating scale for depression. J Neurol Neurosurg Psychiatry 1960 Feb;23:56-62 [FREE Full text] [doi: 10.1136/jnnp.23.1.56] [Medline: 14399272]

86. Hamilton M. The assessment of anxiety states by rating. Br J Med Psychol 1959;32(1):50-55. [doi: 10.1111/j.2044-8341.1959.tb00467.x] [Medline: 13638508]

87. Chisholm D, Knapp MR, Knudsen HC, Amaddeo F, Gaite L, van Wijngaarden B. Client socio-demographic and service receipt inventory--European version: development of an instrument for international research. EPSILON study 5. European psychiatric services: inputs linked to outcome domains and needs. Br J Psychiatry Suppl 2000(39):s28-s33. [doi: 10.1192/bjp.177.39.s28] [Medline: 10945075]

88. Paetzold I, Rauschenberg C, Böcking B, Reininghaus U. EMIcompass. Ein mobiles Training zum Umgang mit Gefühlen. Manual für StudientherapeutInnen. Mannheim: Zentralinstitut für Seelische Gesundheit; 2019.

89. Myin-Germeys I, van Os J, Schwartz JE, Stone AA, Delespaul PA. Emotional reactivity to daily life stress in psychosis. Arch Gen Psychiatry 2001 Dec;58(12):1137-1144. [doi: 10.1001/archpsyc.58.12.1137] [Medline: 11735842]

90. Daemen M, Postma M, Lindauer R, Hoes I, Nieman D, Breedvelt J, et al. Efficacy of a transdiagnostic ecological momentary intervention for improving self-esteem (SELFIE) in youth exposed to childhood adversity: study protocol for a multi-centre randomized controlled trial. PsyArXiv 2020 Oct 01:19 [FREE Full text] [doi: 10.31234/osf.io/a9746]

91. Messner EM, Terhorst Y, Barke A, Baumeister H, Stoyanov S, Hides L, et al. The German version of the Mobile App Rating Scale (MARS-G): development and validation study. JMIR Mhealth Uhealth 2020 Mar 27;8(3):e14479 [FREE Full text] [doi: 10.2196/14479] [Medline: 32217504]

92. Vaessen T, Steinhart H, Batink T, Klippel A, Van Nierop M, Reininghaus U, et al. ACT in daily life in early psychosis: an ecological momentary intervention approach. Psychosis 2019 Mar 19;11(2):93-104. [doi: 10.1080/17522439.2019.1578401]

93. Horwood V, Allan S, Goss K, Gilbert P. The development of the compassion focused therapy therapist competence rating scale. Psychol Psychother 2020 Jun 25;93(2):387-407. [doi: 10.1111/papt.12230] [Medline: $\underline{31021509]}$

94. Harris PA, Taylor R, Thielke R, Payne J, Gonzalez N, Conde JG. Research electronic data capture (REDCap)--a metadata-driven methodology and workflow process for providing translational research informatics support. J Biomed Inform 2009 Apr;42(2):377-381 [FREE Full text] [doi: 10.1016/j.jbi.2008.08.010] [Medline: 18929686] 
95. Myin-Germeys I, Oorschot M, Collip D, Lataster J, Delespaul P, van Os J. Experience sampling research in psychopathology: opening the black box of daily life. Psychol Med 2009 Sep;39(9):1533-1547. [doi: 10.1017/S0033291708004947] [Medline: $\underline{19215626]}$

96. Pries L, Klingenberg B, Menne-Lothmann C, Decoster J, van Winkel R, Collip D, et al. Polygenic liability for schizophrenia and childhood adversity influences daily-life emotion dysregulation and psychosis proneness. Acta Psychiatr Scand 2020 May;141(5):465-475 [FREE Full text] [doi: 10.1111/acps.13158] [Medline: 32027017]

97. Klippel A, Schick A, Myin-Germeys I, Rauschenberg C, Vaessen T, Reininghaus U. Modelling the temporal interplay between stress and affective disturbances in pathways to psychosis: an experience sampling study. Psychol Med 2021 Mar 08:1-10 (forthcoming). [doi: 10.1017/S0033291720004894] [Medline: $\underline{33678198]}$

98. Boyce P, Parker G. Development of a scale to measure interpersonal sensitivity. Aust N Z J Psychiatry 1989 Sep;23(3):341-351. [Medline: 2803146]

99. Connor KM, Davidson JR. Development of a new resilience scale: the Connor-Davidson Resilience Scale (CD-RISC). Depress Anxiety 2003;18(2):76-82. [doi: 10.1002/da.10113] [Medline: 12964174]

100. Leppert K, Koch B, Brähler E, Strauß B. Die Resilienzskala (RS)-Überprüfung der Langform RS-25 und einer Kurzform RS-13. Klinische Diagnostik und Evaluation. 2008. URL: https://docplayer.org/ 67268391-Die-resilienzskala-rs-ueberpruefung-der-langform-rs-25-und-einer-kurzform-rs-13.html [accessed 2021-09-07]

101. Hupfeld J, Ruffieux N. Validierung einer deutschen Version der Self-Compassion Scale (SCS-D). Zeitschrift für Klinische Psychologie und Psychotherapie 2011 Apr;40(2):115-123. [doi: 10.1026/1616-3443/a000088]

102. Baer RA, Smith GT, Lykins E, Button D, Krietemeyer J, Sauer S, et al. Construct validity of the five facet mindfulness questionnaire in meditating and nonmeditating samples. Assessment 2008 Sep;15(3):329-342. [doi: 10.1177/1073191107313003] [Medline: 18310597]

103. Garnefski N, Kraaij V, Spinhoven P. Manual for the Use of the Cognitive Emotion Regulation Questionnaire. The Netherlands: DATEC; 2002.

104. Kwan B, Rickwood DJ. A systematic review of mental health outcome measures for young people aged 12 to 25 years. BMC Psychiatry 2015 Nov 14;15:279 [FREE Full text] [doi: 10.1186/s12888-015-0664-x] [Medline: 26573269]

105. Young RC, Biggs JT, Ziegler VE, Meyer DA. A rating scale for mania: reliability, validity and sensitivity. Br J Psychiatry 1978 Nov 29;133(5):429-435. [doi: 10.1192/bjp.133.5.429] [Medline: 728692]

106. Derogatis L. BSI, Brief Symptom Inventory: Administration, Scoring \& Procedures Manual. Minneapolis, MN: National Computer Systems; 1993.

107. Beck AT, Steer RA, Ball R, Ranieri W. Comparison of Beck Depression Inventories -IA and -II in psychiatric outpatients. J Pers Assess 1996 Dec;67(3):588-597. [doi: 10.1207/s15327752jpa6703_13] [Medline: 8991972]

108. Loewy RL, Bearden CE, Johnson JK, Raine A, Cannon TD. The prodromal questionnaire (PQ): preliminary validation of a self-report screening measure for prodromal and psychotic syndromes. Schizophr Res 2005 Sep 15;77(2-3):141-149. [doi: 10.1016/j.schres.2005.03.007] [Medline: 15905071]

109. Skevington SM, Lotfy M, O'Connell KA, WHOQOL Group. The World Health Organization's WHOQOL-BREF quality of life assessment: psychometric properties and results of the international field trial. A report from the WHOQOL group. Qual Life Res 2004 Mar;13(2):299-310. [doi: 10.1023/B:QURE.0000018486.91360.00] [Medline: 15085902]

110. Bernstein DP, Stein JA, Newcomb MD, Walker E, Pogge D, Ahluvalia T, et al. Development and validation of a brief screening version of the Childhood Trauma Questionnaire. Child Abuse Negl 2003 Feb;27(2):169-190. [doi: 10.1016/S0145-2134(02)00541-0]

111. Hatcher RL, Lindqvist K, Falkenström F. Psychometric evaluation of the Working Alliance Inventory-Therapist version: current and new short forms. Psychother Res 2020 Jul;30(6):706-717. [doi: 10.1080/10503307.2019.1677964] [Medline: 31621525]

112. Hatcher RL, Gillaspy JA. Development and validation of a revised short version of the working alliance inventory. Psychother Res 2006 Jan;16(1):12-25. [doi: 10.1080/10503300500352500]

113. Reininghaus U, Paetzold I, Rauschenberg C, Hirjak D, Banaschewski T, Meyer-Lindenberg A, et al. The effects of a novel, transdiagnostic, hybrid ecological momentary intervention for improving resilience in youth (EMIcompass): data analysis plan for an exploratory randomized controlled trial. OSF Registries. 2021. URL: https://archive.org/details/ osf-registrations-a624y-v1 [accessed 2021-08-06]

114. Hunot V, Moore TH, Caldwell DM, Furukawa TA, Davies P, Jones H, et al. 'Third wave' cognitive and behavioural therapies versus other psychological therapies for depression. Cochrane Database Syst Rev 2013 Oct 18;10(10):CD008704. [doi: 10.1002/14651858.CD008704.pub2] [Medline: 24142844]

115. Zhang Z, Zyphur MJ, Preacher KJ. Testing multilevel mediation using hierarchical linear models. Organ Res Methods 2008 Dec 17;12(4):695-719. [doi: 10.1177/1094428108327450]

116. Bakker D, Kazantzis N, Rickwood D, Rickard N. Mental health smartphone apps: review and evidence-based recommendations for future developments. JMIR Ment Health 2016 Mar 01;3(1):e7 [FREE Full text] [doi: 10.2196/mental.4984] [Medline: 26932350] 
117. Waller H, Garety PA, Jolley S, Fornells-Ambrojo M, Kuipers E, Onwumere J, et al. Low intensity cognitive behavioural therapy for psychosis: a pilot study. J Behav Ther Exp Psychiatry 2013 Mar;44(1):98-104. [doi: 10.1016/j.jbtep.2012.07.013] [Medline: 22940787]

118. Waller H, Garety P, Jolley S, Fornells-Ambrojo M, Kuipers E, Onwumere J, et al. Training frontline mental health staff to deliver "low intensity" psychological therapy for psychosis: a qualitative analysis of therapist and service user views on the therapy and its future implementation. Behav Cogn Psychother 2015 May;43(3):298-313. [doi: 10.1017/S1352465813000908] [Medline: 24152370]

119. Steinhart H. Same same but different; psychological interventions and how to mind the knowledge practice gap. KU Leuven. 2018. URL: https://lirias.kuleuven.be/2343088?limo=0 [accessed 2021-09-07]

120. Palmier-Claus JE, Dunn G, Lewis SW. Emotional and symptomatic reactivity to stress in individuals at ultra-high risk of developing psychosis. Psychol Med 2012 May;42(5):1003-1012. [doi: 10.1017/S0033291711001929] [Medline: 22067414]

121. Koppe G, Guloksuz S, Reininghaus U, Durstewitz D. Recurrent neural networks in mobile sampling and intervention. Schizophr Bull 2019 Mar 07;45(2):272-276 [FREE Full text] [doi: 10.1093/schbul/sby171] [Medline: 30496527]

122. Reininghaus U, Böhnke JR, Chavez-Baldini U, Gibbons R, Ivleva E, Clementz BA, et al. Transdiagnostic dimensions of psychosis in the Bipolar-Schizophrenia Network on Intermediate Phenotypes (B-SNIP). World Psychiatry 2019 Feb;18(1):67-76 [FREE Full text] [doi: 10.1002/wps.20607] [Medline: 30600629]

123. Morgan C, Lappin J, Heslin M, Donoghue K, Lomas B, Reininghaus U, et al. Reappraising the long-term course and outcome of psychotic disorders: the AESOP-10 study. Psychol Med 2014 Oct;44(13):2713-2726 [FREE Full text] [doi: 10.1017/S0033291714000282] [Medline: 25066181]

\author{
Abbreviations \\ CBT: cognitive behavioral therapy \\ CHARMS: Clinical High At-Risk Mental State \\ CIMH: Central Institute of Mental Health \\ DSM-5: Diagnostic and Statistical Manual of Mental Disorders \\ DMEC: Data Monitoring and Ethics Committee \\ EC: ethics committee \\ ECG: electrocardiography \\ EMA: ecological momentary assessment \\ EMI: ecological momentary intervention \\ mHealth: mobile health \\ PI: principal investigator \\ RCT: randomized controlled trial \\ REDCap: Research Electronic Data Capture \\ SAE: serious adverse event \\ TAU: treatment as usual \\ TSC: Trial Steering Committee
}

Edited by G Eysenbach; submitted 31.01.21; peer-reviewed by L Valmaggia, J Smyth, J Scott; comments to author 06.04.21; revised
version received 31.05.21; accepted 11.08.21; published 03.12.21
Please cite as:
Schick A, Paetzold I, Rauschenberg C, Hirjak D, Banaschewski T, Meyer-Lindenberg A, Boehnke JR, Boecking B, Reininghaus U
Effects of a Novel, Transdiagnostic, Hybrid Ecological Momentary Intervention for Improving Resilience in Youth (EMIcompass):
Protocol for an Exploratory Randomized Controlled Trial
JMIR Res Protoc 2021;10(12):e27462
URL: https://www.researchprotocols.org/2021/12/e27462
doi: $10.2196 / 27462$
PMID:

(C)Anita Schick, Isabell Paetzold, Christian Rauschenberg, Dusan Hirjak, Tobias Banaschewski, Andreas Meyer-Lindenberg, Jan $\mathrm{R}$ Boehnke, Benjamin Boecking, Ulrich Reininghaus. Originally published in JMIR Research Protocols (https://www.researchprotocols.org), 03.12.2021. This is an open-access article distributed under the terms of the Creative Commons Attribution License (https://creativecommons.org/licenses/by/4.0/), which permits unrestricted use, distribution, and reproduction in any medium, provided the original work, first published in JMIR Research Protocols, is properly cited. The 
complete bibliographic information, a link to the original publication on https://www.researchprotocols.org, as well as this copyright and license information must be included. 